\title{
Roberto Carlos e a identidade brasileira na canção ${ }^{1}$
}

\author{
Acauam Oliveira ${ }^{2}$
}

Resumo

Roberto Carlos é, ao mesmo tempo, o mais popular e o mais rejeitado dos artistas brasileiros. Nosso artigo pretende compreender as raízes dessa contradição, compreendendo tanto a positividade e o valor de sua obra - buscando relativizar uma série de estigmas e preconceitos que rondam sua figura, demonstrando, por assim dizer, a legitimidade de sua coroa - quanto o lugar a partir de onde falam seus antagonistas, de modo a perceber o conjunto de interesses e posições envolvidas nesses juízos críticos.

\section{Palavras-chave}

Roberto Carlos, cultura de massas, MPB, samba.

Recebido em 22 de setembro de 2011

Aprovado em 8 de dezembro de 2011

1 Este texto faz parte do projeto de pesquisa de doutorado sobre a canção popular urbana do Brasil e a constituição de seus critérios de valoração estética, sob a orientação do Prof. Dr. José Miguel Wisnik.

2 Participa do programa de doutorado do Departamento de Literatura Brasileira da Universidade de São Paulo. E-mail: acauam@gmail.com 


\title{
Roberto Carlos and Brazilian Identity in Song
}

\author{
Acauam Oliveira
}

Abstract

Roberto Carlos is at once the most popular and most widely rejected of Brazilian artists. The paper aims to understand the roots of this contradiction, including both the positives and value of his work trying to relativize a number of stigmas and prejudices that surround his figure, and demonstrate, so to speak, the legitimacy of his crown - and, on the other hand, the standpoints of his detractors, in order to reveal the set of interests and positions that undergird these critical judgments.

\section{Keywords}

Roberto Carlos, mass culture, MPB, samba. 


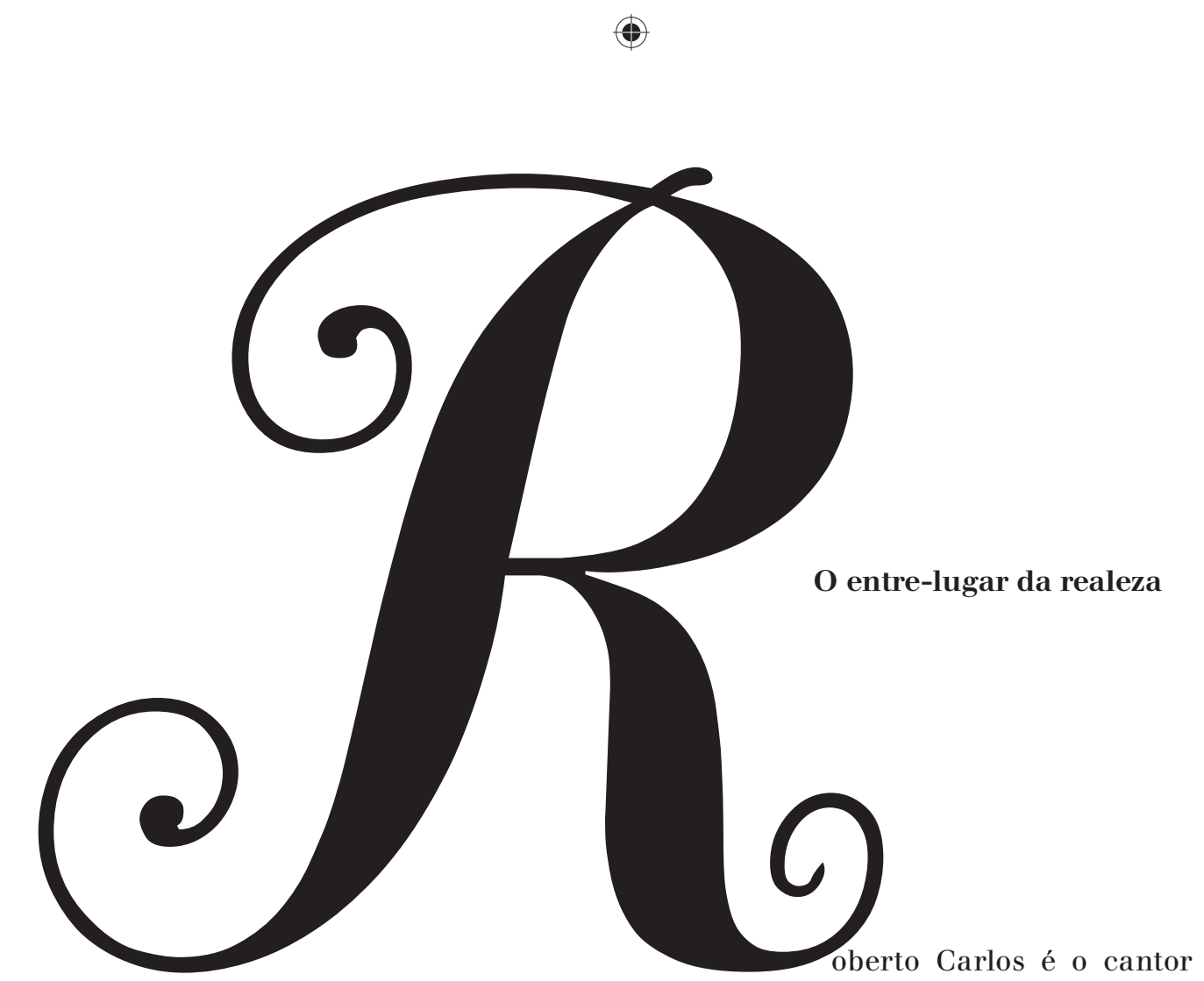

de maior sucesso do Brasil. Sua popularidade é incontestável, atestada por seus impressionantes números de vendas - é o mais vendido do Brasil - e por sua ampla difusão no contexto popular, sendo, por exemplo, um dos raríssimos casos de um cancionista que possui um programa de rádio dedicado inteiramente a sua obra. E não apenas em uma, mas em diversas cidades brasileiras, especialmente no Nordeste. Tudo o que se refere a sua difusão e penetração na cultura popular - desde o início de sua carreira, mas especialmente quando, a partir dos anos 1970, decide investir no gênero romântico - assume dimensões continentais ${ }^{5}$.

Por outro lado, e talvez na mesma proporção de sua ampla difusão, é notório o sentimento de rejeição em torno de sua figura, desde a época da Jovem Guarda. Para muitos críticos, formadores de opinião em geral e artistas relacionados a certa linhagem da música brasileira, RC é o maior representante da música de massas, cujas principais características seriam sua baixa qualidade e ampla difusão. Note-se que, na época da Jovem Guarda, somava-se a isso uma convicção - que em certa medida permanece até os dias de hoje em alguns círculos - de que tais composições serviam aos interesses das alas mais conservadoras da sociedade. Para o historiador Marcos Napolitano:

3 Para maiores detalhes, ver SANCHES, P. A. Como dois e dois são cinco. São Paulo: Boitempo, 2004; e ARAÚJO, P. C. Roberto Carlos em Detalhes. São Paulo: Editora Planeta, 2006.

153

revista ieb $n_{54} 2012$ set./mar. p. I5I-I66 
O "movimento" da Jovem Guarda era relacionado aos efeitos de "entreguismo" cultural e "alienação" política no seio da juventude e, neste sentido, a ponta de lança dos militares na guerrilha cultural que o país parecia vivenciar (...). Sua pobreza formal e de conteúdos e a "alienação" diante dos dilemas enfrentados pela nação eram vistas como a antítese da MPB, elementos constantemente denunciados pelos artistas engajados. ${ }^{4}$

Para essa linha de pensamento, RC é artista menor porque faz música de massa, mera reprodução dos mecanismos de autorreprodução do sistema capitalista no plano cultural, estando, consequentemente, alienado dos problemas políticos e sociais do país. A fragilidade dessa produção seria, pois, de mão dupla. Uma de ordem interna, no plano da organização dos elementos, e outra de ordem externa, da inorganicidade com a matéria histórica. O resultado é uma obra que, além de mal resolvida estruturalmente, tem pouco a dizer sobre nós mesmos, mantendo um caráter meramente ornamental.

A partir dessa perspectiva, encontrar qualidades na produção de RC ou em outras qualificadas como românticas, ou "bregas", é por vezes sentido como uma espécie de traição, ou desqualificado enquanto gesto provocativo inconsequente. Conforme salienta Paulo César Araújo:

Em todos os campos da música popular há artistas de maior ou menor talento e composições de boa ou má qualidade. Mas, em relação ao estilo brega, os críticos cometem um flagrante exagero: eles rejeitam o estilo em si, desqualificando quem o utiliza. ${ }^{5}$

Ou seja, muito mais do que uma postura crítica reflexiva, tal gesto revela determinada convicção ideológica, que convém ser explicitada.

Nosso objetivo principal será, pois, tensionar certa linha de leitura hegemônica da canção no Brasil a partir da consideração de um de seus grandes Outros, no caso, Roberto Carlos. Interessa questionar a construção de sua figura (e de certa parcela da música popular) como inautêntica, por supostamente não participar da linha formativa de nossa identidade nacional musical, cujo epicentro é composto pela tríade samba, bossa nova,

4. NAPOLITANO, M. Seguindo a canção: engajamento político e indústria cultural na trajetória da Música Popular Brasileira (1959-1969). São Paulo, 1998. Tese (Doutorado) - Faculdade de Filosofia, Letras e Ciências Humanas, Universidade de São Paulo; Seguindo a canção: engajamento político e indústria cultural na MPB (1959/1969). São Paulo: Annablume/Fapesp, 2001.

5 ARAÚJO, P. C. Waldick Soriano e o mistério do brega. Revista USP, São Paulo, n. 87, nov. 2010. 
$\mathrm{MPB}^{6}$. Não queremos com isso forçar uma aproximação do romantismo carlista com essa linha de força, o que terminaria por mantê-la enquanto lugar de legitimação por excelência. Pelo contrário, o objetivo é deslocar o campo discursivo a partir de onde se criam os mecanismos de distinção e atribuição de valor, revelando as fissuras desse discurso e os movimentos ideológicos que o sustentam.

Ou seja, o que se propõe é um modelo de crítica ideológica, a partir principalmente da revisão que o conceito sofre com autores como Slavoj Zizek $^{7}$ e Terry Eagleton, ${ }^{8}$ que compreendem o ideológico não apenas como uma espécie de enunciado constativo, analisável segundo critérios de verdade e falsidade, mas enquanto uma prática simbólica performativa. A ideologia não está apenas nos conteúdos dos discursos (saber se RC é ou não conservador), mas sobretudo no sistema (ou instituições, nos termos com que Althusser define os Aparelhos Ideológicos de Estado) que organiza e valoriza esses conteúdos, criando mecanismos de distinção. Não se trata de afirmar o projeto estético de Roberto Carlos como não ideológico, mas verificar a partir de sua obra quais são os valores e exclusões que essa narrativa hegemônica da formação da música nacional realiza para se sustentar, e quais os mecanismos de poder implícitos nesse processo.

\section{Os mitos da modernidade na canção popular}

Desde seu primeiro LP voltado para o rock (Roberto Carlos, 1963), claramente arquitetado por Carlos Imperial na bem-sucedida tentativa de criar uma versão nacional do pop rock americano, RC é ao mesmo tempo sucesso de vendas (são desse álbum os grandes sucessos "Parei na contramão" e "Splish splash") e alvo de críticas, especialmente por parte dos adeptos da então MPB. Críticas essas que só tenderam a aumentar com a radicalização do processo político e dos ânimos no âmbito da cultura.

Em maio de 1966, foi promovido e publicado um debate pela Revista Civilização Brasileira, em que se discutiam quais os caminhos da MPB. Os participantes desse debate foram Caetano Veloso, Nelson Lins e Barros, Nara Leão, Gustavo Dahl, Flávio Macedo Regis, José Carlos Capinan e Ferreira Gullar, e os temas debatidos refletiam as inquietações de boa

6 "Para dar nome às coisas, poderíamos dizer que há uma linha formativa da nossa tradição musical popular, que acabou por ser fundamental para a nossa autoimagem musical (...). Esse alinhavo passa por três gêneros (...) samba, bossa nova e MPB”. (NAPOLITANO, Marcos. A síncope das ideias. São Paulo: Editora Fundação Perseu Abramo, 2007).

7 ZIZEK, S. O espectro da ideologia. In:___. Um mapa da ideologia. Rio de Janeiro: Contraponto, 1996.

8 EAGLETON, T. Ideologia: uma introdução. São Paulo: Boitempo, 1997. 
parte de artistas e intelectuais engajados na época. O combustível inicial do debate foi "o temor que os entusiastas da MPB sentiam do rock brasileiro", capitaneado pelo então rei da juventude. Nele podemos perceber que, por detrás da maior parte das críticas, a noção de importação ocupa lugar de destaque, sendo aquilo que irá retirar definitivamente a produção de RC do caminho proposto pela chamada linha evolutiva da música popular brasileira, termo cunhado por Caetano Veloso nesse mesmo debate ${ }^{10}$. Nas palavras de Capinan, já em 1967:

Inclusive não se discute se o iê-iê-iê é válido ou não no Brasil. O que devemos manter como ponto de comum atitude é a resistência a que ele seja aceito como cultura brasileira, como resposta necessária da atual conjuntura. A forma como o capital estrangeiro participa de nossa economia faz com que a maior parte de nossos problemas seja confundida com os problemas exteriores, de nações bem mais aparelhadas para enfrentá-los e bem mais responsáveis por esses problemas. E assim como os problemas, a nossa arte que está ligada a eles tende a ser um falso produto, motivada por procedimentos estranhos e numa linguagem que nada tem a ver com nossa cultura. A nossa música pode apreender do iê-iê-iê muita coisa, mas não pode ser substituída por ele. ${ }^{11}$

O principal problema com a produção de RC, dessa perspectiva, é seu caráter de importação direta de modas e procedimentos estéticos que, obedecendo mais ao ritmo das mercadorias que a uma real necessidade de desenvolvimento dos materiais, não leva em consideração a necessidade de ressignificação local dessas formas. Trocando uma moda importada por outra, RC produziria um conjunto de canções descartáveis que só sobrevivem por seu alto teor de exposição, confundindo definitivamente repetição com padrão de gosto, num exemplo perfeito do esquema clássico de funcionamento da Indústria Cultural: repetição, reconhecimento, acei-

9 NAPOLITANO, Marcos. A sincope das ideias. op. cit.

10 Nessa linha evolutiva estariam envolvidos todos aqueles artistas que contribuíram para a formação da canção brasileira, uma forma estética que comporte em si as contradições do processo histórico local. É desse modo que se explica como João Gilberto, mesmo fazendo uso de procedimentos estrangeiros em seu processo de composição, conseguia manter a excelência da sua obra, visto que tais aspectos eram ressignificados no interior de um sistema conectado com o paradigma cancional brasileiro, modernizando-o.

11 ALVES, V. A. Torquato Neto e o debate sobre a música popular brasileira no Jornal dos sports - 1967. Anais do XX Encontro Regional de História. ANPUH/SP, Unesp/Franca, 2010. 
tação ${ }^{12}$. Note-se que, mesmo no último período do texto, em que Capinan adota uma postura mais "tropicalista", a Jovem Guarda em si continua sendo rejeitada, só sendo aceitável após um processo de transformação crítica, ou antropofágica. Mesmo após o período de importação direta do rock, RC continuaria sendo acusado de fazer uma música que macaqueava gêneros internacionais como o bolero, ou música americana.

Sem negar essa dimensão mercadológica negativa da obra de RC, que em muitos momentos de fato obedece a esse princípio de estandardização reificada, é preciso prestar muita atenção ao seguinte aspecto da questão. Concordamos com a perspectiva materialista, para a qual é decisivo o problema de adequação formal à matéria histórica, com riscos de mitificação do material estético em um universalismo reificador. Entretanto, as formas possíveis dessa adequação estão sempre em aberto e, a partir do momento em que se parte para uma definição dos conteúdos tanto do nacional quanto dos respectivos modelos de adequação, corre-se o risco de transformar uma perspectiva especificamente ligada a determinado contexto em representante da totalidade. Ou seja, ideologia.

Esse é, aliás, o ponto central da crítica tropicalista a uma definição mais rígida de música brasileira. Para os tropicalistas, a sonoridade brasileira era composta tanto pelas sonoridades rurais quanto pelas urbanas e as estrangeiras. Nesse sentido é que o grupo baiano iria aproximar-se de RC. Entretanto, ainda aqui, existe certo distanciamento, pois a obra que será enquadrada no interior da linha evolutiva não é exatamente a de Roberto Carlos, um bolero ou um iê-iê-iê na roupagem "brega" de RC, mas sua versão adaptada, via padrões estéticos da MPB. Os tropicalistas representam um grande avanço crítico no sentido de questionar uma noção essencialista de brasilidade que determinava parte da produção artística. Por outro lado, tal movimento não é suficiente para inserir o autor no cânone do alto escalão da música brasileira, porque sua obra não iria deglutir de forma crítica a informação externa, assumindo um caráter marcadamente mercadológico.

O movimento ideológico decisivo, nesse caso, está na distribuição dos papéis e dos prêmios no interior da música brasileira, a distinção entre os primeiros lugares e quem "corre por fora", estabelecendo uma narrativa linear em que as continuidades interessam mais que as rupturas. No caso específico de RC, toda a tradição de música romântica nacional, que passa pela modinha, pelo bolero, pelo samba-canção, pela cancione italiana etc., formas no geral desconsideradas a partir do critério de mau gosto e inadequação, é colocada em segundo plano em relação à verdadeira canção brasileira (de qualidade), que passa do maxixe para o samba e daí para a

12 ADORNO, T. O fetichismo na música e a regressão da audição. In: Os pensadores - Adorno. São Paulo: Nova Cultural, 1999 
MPB, na construção narrativa da modernidade brasileira via canção, que cria ao mesmo tempo suas rupturas (MPB) e origens (samba). Em certo sentido, tal movimento permanece mesmo no deslocamento tropicalista, que "libera" essas formas para serem reconfiguradas no interior do padrão MPB, mas sem retirar do centro esse processo "antropofágico".

É necessário, portanto, deslocar imediatamente os lugares reservados tanto para RC quanto para o "segundo escalão" da música brasileira, perguntando-se em que medida tais gêneros constroem um modelo narrativo alternativo de compreensão da história da música popular, e da própria configuração do país. Obedecendo a quais ordens de interesses é criado esse princípio classificatório hegemônico? Vejamos, pois, dois dos principais mitos que sustentam a legitimação do "primeiro escalão" da música popular brasileira - a noção de autoria (subjetividade crítica moderna) e a noção de origem (tradição) - e de que maneira a obra de RC contrapõe-se a esses critérios ${ }^{15}$.

\section{O mito da autoria}

Como vimos, a recepção crítica de Roberto Carlos por parte de artistas e intelectuais adeptos do modelo MPB passa necessariamente pela questão da importação (bem evidente no período Jovem Guarda, mas que se manteve com a opção do artista pela música romântica de arranjos orquestrais não percussivos, de inspiração americana), e de sua alegada incapacidade de se apropriar da matéria externa de forma crítica. Tal exigência tem por pressuposto implícito a ideia de um sujeito que organize esse material e lhe confira novo significado, a partir de um projeto de ordenação estrutural. Uma subjetividade "forte", crítica e moderna, que faça contraponto artístico às necessidades puramente mercadológicas. Essa seria a base do procedimento de João Gilberto, segundo a interpretação da linha evolutiva de Caetano. Em suma, a estratégia de legitimação dessa posição passa pela afirmação de determinada concepção de Autor (o samba procura legitimar-se a partir de outro princípio, como veremos), que possibilitaria a reordenação dos elementos em uma obra, até certo ponto, autônoma. RC não entraria

13 "Mas, então, onde estaria o mistério do brega? Por que alguns cantores são rotulados as sim e outros não? Eu defendo a tese de que brega é toda aquela produção musical que as elites culturais do Brasil não identificam ao que se considera tradição (folclore, música caipira, choro, forró pé-de-serra, marchinhas carnavalescas, samba de raiz) nem ao que se considera 'modernidade' (vanguardas, jazz, bossa nova, tropicalismo, rock inglès). E esse é o principal parâmetro de julgamento estético de uma obra musical no Brasil. Para ser bem qualificada pela crítica ou aceita pelas elites culturais, uma música precisa estar identificada a uma dessas vertentes. Quem não se enquadra na tradição ou na modernidade é considerado ruim, brega, cafona". (ARAÚJO, P. C. op. cit.) 
nesse campo de representação, produzindo consequentemente uma obra de baixo potencial estético, mera reprodução de critérios mercadológicos.

Entretanto, a questão se complica quando pensamos que, em certo sentido, a própria forma canção brasileira constitui-se a partir de um princípio que não obedece ao de autonomia, relativizando a própria função Autor, que não pode então ser tomada como critério de valoração estendível a toda a produção estética nacional.

O estabelecimento desse tipo de racionalidade no campo da canção popular se dá a partir dos anos 1950 com a turma da Bossa Nova, e consagra-se com a geração MPB, inaugurando o que se costuma chamar de modernização da canção popular brasileira. Com sua revolucionária batida de violã $0^{14}$, e seu modo novo de pensar a matéria musical, João Gilberto inaugura uma nova postura diante da canção, tomada agora como resultante de um trabalho intelectual crítico. Com ela, o como se $f a z$ passa à frente do que se faz - ou seja, aquilo que até então estava ao fundo no projeto do cancionista passa à frente. Por isso a MPB, enquanto herdeira do gesto da Bossa Nova, será prioritariamente um modo de fazer, que insere no campo da canção brasileira a noção de autor (no mesmo sentido em que se usa o conceito de cinema de autor, em contraposição ao comercial), recuperando no interior desta uma concepção de autonomia possível. MPB é, pois, no limite, um conceito amplo que tem a capacidade de comportar quaisquer gêneros existentes, desde que, por detrás de tudo, esteja em operação uma consciência crítica reflexiva (ao menos seguindo a leitura de alguns de seus atores e críticos). Esse sujeito estilizará o material primário, seja "folclórico" ou não (no caso dos tropicalistas), e irá reorganizá-lo de forma consciente, em torno de um projeto estético que escape das limitações de gênero e das imposições do mercado, uma forma cujo sentido esteja em seu próprio desenvolvimento interno.

Entretanto, acreditamos que a canção ocupa um patamar diferenciado em relação às formas autônomas como a literatura, justamente porque seu princípio de constituição não se sustenta completamente na noção de autonomia. A formação da canção no Brasil desde seus primórdios deu-se em direção a um princípio heterônomo de constituição, ou seja, uma forma "aberta" em que os elementos externos participam ativamente de seu princípio constitutivo, não sendo possível a delimitação das características de um dado gênero exclusivamente a partir dos seus elementos estruturais internos ${ }^{15}$.

14. Uma análise profunda dos traços inovadores, assim como das possíveis influências dessa batida pode ser encontrada em GARCIA, Walter. Bim Bom: A contradição sem conflitos de João Gilberto. São Paulo: Paz e Terra, 1999.

15 Veja essa discussão com relação ao maxixe em MACHADO NETO, C. G. O enigma do homem célebre: ambição e vocação em Ernesto Nazareth (1863-1934). Tese de doutorado 
Essa concepção formal heterônoma pode ser compreendida a partir de três princípios básicos de constituição da canção, explicitados por Luis Tatit ${ }^{16}: 0$ desenvolvimento de uma linguagem baseada no princípio de estabilização do modo de dizer do português brasileiro em uma forma estética que não perde de vista seu lastro entoativo, ligado a necessidades práticas cotidianas; a não institucionalização do saber necessário para o domínio dos procedimentos destinados à confecção da canção, responsável por seu alto grau de penetração e organicidade em um país marcado pelo profundo afastamento da sociedade em relação ao campo dos saberes formais; e o grau de desenvolvimento dos meios de produção da sociedade e da indústria fonográfica, responsável pela possibilidade de gravação do registro oral diretamente, sem a necessidade de formas de mediação escritas.

Essa "abertura", esse modelo heterônomo de organização - cujo grande avanço se faz sentir na inclusão decisiva daqueles que tradicionalmente não têm voz -, é em grande medida responsável pelo potencial de grande parte da canção popular brasileira, uma das bases de sua originalidade e força. Modelo que se afasta da concepção mais autônoma de autoria proposta pela MPB, utilizada para desqualificar a produção de Roberto Carlos. Critérios como consciência crítica e autonomia estética, portanto, não podem servir como único parâmetro de análise de canções de gêneros tão distintos como o samba, maracatu, bolero, choro, marchinha, guarânia, iê-iê-iê, sertanejo, pagode, entre tantos outros ${ }^{17}$. Superdimensionar esse gesto por um excesso de criticidade acaba por tornar o próprio gesto crítico conteúdo ideológico.

\section{O mito da origem}

Mas existem outros lugares legitimados na música popular a partir de onde a produção de RC pode ser considerada inautêntica. $\mathrm{O}$ samba, por exemplo, não partilha do princípio de autoria - Sinhô, um dos responsáveis

apresentada ao departamento de Letras da USP. Algo semelhante propõe Antonio Cícero ao discutir o caráter sintético do desenvolvimento da música popular, em oposição ao caráter analítico do desenvolvimento da música erudita. (CÍCERO, A. O tropicalismo e a MPB. In: DUARTE, P. S.; NAVES, S. C. (org.). Do samba-canção à Tropicália. Rio de Janeiro: Relume Dumará, 200z.)

16 TATIT, Luis. O cancionista: composição de canções no Brasil. São Paulo: Edusp, 1996.

17 "O alerta, portanto, é para que a recepção crítica de João Gilberto não incorra nessa espécie curiosa de phonocentrismo, ou seja, um privilégio concedido à fala [phoné], não por suas propriedades metafísicas - a presença, a imaterialidade, o não empírico, o não contingente - como demonstrou Derrida, mas por uma interpretação essencialista de um gesto histórico". (BOSCO, F. Cinema-canção. In: NESTROVSKI, A. (org.). Lendo música. São Paulo: Publifolha, 2007.) 
pela difusão em massa do gênero, lançava um politicamente incorreto "samba é que nem passarinho, de quem pegar primeiro" - tal como colocado pela MPB. Muito de sua força está na criação daquela forma heterônoma de que falamos acima, estabelecendo formas de fixação da fala que mantêm o esquema de improvisação da roda de samba. Nesse esquema, mantido até hoje em alguns contextos, cria-se o refrão, cantado coletivamente, e depois é fixada uma grade melódica a partir da qual os participantes podem criar versos, relacionados com o tema proposto. Mesmo quando um samba desses é fixado em uma gravação, os elementos derivados da oralidade são mantidos, sendo no mínimo arbitrário considerar que está presente ali uma subjetividade racionalizadora em sentido forte, por melhor e mais bem estruturado que esteja. Desnecessário dizer, também, que nem todo samba é assim.

Entretanto, outro mito sustenta o lugar de legitimidade do samba, que sobrevive a partir da definição de sua autenticidade. $O$ mito de origem está na base mesma de sua constituição enquanto gênero. Desde que o samba principiou a ser gravado, recebendo maior atenção, o debate sobre qual seria o mais verdadeiro, autêntico ou brasileiro está colocado. A partir dos anos 1950, com os chamados folcloristas urbanos, "surgiu uma tendência crítica importante e pouco lembrada, que praticamente reinventou a tradição musical brasileira" ${ }^{18}$. Esses críticos desvalorizavam a produção contemporânea marcada pela ampliação do mercado fonográfico e idealizavam um tempo instituinte do samba, a época de ouro dos anos 1930. Concepção que se tornou hegemônica.

Ou seja, desde seu nascimento até os dias de hoje, o samba coloca em questão as suas origens, em busca por legitimidade: variação do maxixe, dos batuques de candomblé, da África, do Rio, da Bahia, do morro, da cidade, cozinha em destaque ou harmonia em destaque? Podemos dizer que esse movimento é inerente à própria canção, e aos gêneros mais heterônomos em particular, visto serem indefiníveis do ponto de vista meramente estrutural. Não é possível definir o gênero a partir de formas, estilos ou instrumentação, porque todos esses elementos são cambiáveis e definíveis a partir de um processo social em permanente disputa. Dessa perspectiva, o samba é muito mais um "lugar", formado a partir de inúmeras variantes que envolvem status, performance, melodia, harmonia, instrumental, agentes, momento histórico, etc. O que é samba genuíno hoje pode não ter sido ou pode deixar de ser, ou pode ainda suscitar debates eternos sobre seu verdadeiro lugar. O que existe é um conjunto heterogêneo de estilos e formas que compartilham e trocam elementos de composição, buscando espaço de legitimação.

18 Idem, ibidem, p. 62.

I6I

revista ieb $n_{54} 2012$ set./mar. p. I5I-I66 
Toda busca de definição pelas origens do samba comporta um componente ideológico de afirmação no interior de um campo. Por exemplo, quando, a partir dos anos 1930, o paradigma do Estácio foi eleito como uma matriz rítmica mais legítima para representar o samba (afastando-se do maxixe para se aproximar da marcha) em escala nacional, uma série de outros formatos (samba-raiado, samba de lenço, samba--chula, samba de bumbo, samba-rural) foram expulsos do interior dessa configuração - a partir de então considerada mais legítima - e relegados ao plano do folclórico. Por outro lado, esse mecanismo de definição ideológica do que seja o samba autêntico é absolutamente imprescindível para que o gênero possa existir enquanto tal. Por mais abertas que sejam tais negociações, e por mais que, no limite, uma definição restritiva definitiva seja contrária ao próprio formato de constituição do estilo, a contraparte inevitável é que se realize esse movimento, definidor não do formato samba, mas do seu "lugar", sem o qual a própria noção de gênero deixa de fazer sentido. O que faz o disco de estreia de Chico Buarque, composto só de sambas, não ser obra de um sambista, e o que faz uma compositora que flerta todo o tempo com a MPB como Clara Nunes ser vista como tal depende dessas definições, que não são nem meramente mercadológicas e nem precisamente definíveis.

Sendo assim, a afirmação de que o samba é um gênero mais legítimo que a importação de RC se torna dificilmente sustentável. Afinal, não existe um único samba, mas diversos sambas em disputa por legitimação e espaço. O samba não possui uma origem única, o Brasil, porque este é um espaço também híbrido de constituição, renegociado a cada momento, apesar de não existir para além desse movimento de negociação que é ideologicamente concreto. E se a ideia de origem é fruto dessas negociações, como dizer que $o$ autor mais difundido do país, maior nome do estilo musical que mais vende discos no Brasil, é menos popular, ou legítimo? Como afirmar que o samba é mais propriamente nosso se ele cria a noção de um "nós" na exata medida em que se constitui, assim como RC? O quadro se complica.

\section{Nobreza indigesta: Roberto Carlos e o Brasil}

O que procuramos realizar até agora foi uma espécie de mapeamento dos lugares a partir de onde são construídos dois dos principais discursos de desqualificação de Roberto Carlos - que não são os únicos, digamos desde já, inserindo elementos de tensão no interior da narrativa que considera a tríade samba-bossa nova-MPB como o tripé central de nossa formação musical. Vimos que a questão decisiva passa pelo problema da "importação": RC nem trabalha com a matéria tradicional

revista ieb $\quad$ n54 2012 set./mar. p. I5I-I66 
brasileira, nem incorpora criticamente a matéria importada, criando uma obra inautêntica.

Afirmar que o estilo de RC é tão adequado ou "próprio" quanto outros não significa eliminar a questão da adequação da forma à matéria local, tema clássico de toda uma tradição de pensamento brasileiro que passa por nomes como Antonio Candido e Roberto Schwarz. Existem, sim, inúmeros exemplos de canções mal estruturadas por não atentarem para as contradições locais, resultando numa espécie de pastiche mal elaborado.

A questão não é, pois, a inexistência do problema, e sim o modo como ele é rearticulado no mecanismo de desqualificação de RC, ou seja, a partir de onde se inscrevem essas críticas e em nome do que elas são feitas. Nesse caso, a leitura é fruto de uma tomada de posição e de uma construção ideológica que definem quais são os elementos que devem ou não participar do conceito de nação e do cânone da música popular, e quais devem ser excluídos ou dissimulados, ocultando aspectos por assim dizer menos "interessantes" de nossa constituição ${ }^{19}$. Por limitações de espaço, iremos nos concentrar nos aspectos ideológicos da relação de Roberto Carlos com certa concepção de brasilidade, deixando para uma próxima oportunidade uma análise formal mais detida, que relativizaria a noção de pastiche mercadológico em sua obra.

No caso da crítica que acompanhamos, os padrões valorizados são ou o sujeito moderno crítico e reflexivo, em geral de classe média, representada pela MPB, ou o sujeito tradicional, representado pelo samba autêntico. Todos os demais estilos são desqualificados enquanto produtos alienados e de baixo valor, mero consumo acrítico de formas importadas. Ocorre uma inversão perversa - não incomum em país de maioria iletrada -, em que a cobrança por consciência crítica se transforma em mecanismo de dominação e de suspensão da própria crítica - a partir do momento em que as regras de tal consciência são definidas e impostas de cima para baixo. É possível existir arte de qualidade sem crítica e sem raízes nacionais? Arte sem qualidade é arte? É possível entretenimento de qualidade? Questões como essa são descartadas de antemão pela academia, onde predomina a pesquisa de temas consagrados seja pelo pensamento da tradição, como o choro ou o samba, seja pelo da modernidade, como os festivais e compositores engajados dos anos 1960 e 1970.

19 “Assim, uma ideologia não é necessariamente 'falsa': quanto a seu conteúdo positivo, ela pode ser 'verdadeira', muito precisa, pois o que realmente importa não é o conteúdo afirmado como tal, mas o modo como esse conteúdo se relaciona com a postura subjetiva envolvida em seu próprio processo de enunciação. Estamos dentro do espaço ideológico propriamente dito no momento em que esse conteúdo - 'verdadeiro' ou ‘falso' (se verdadeiro, tanto melhor para o efeito ideológico) - é funcional com respeito a alguma relação de dominação social (poder, exploração).” (ZIZEK, S. op. cit.) 
A imagem de país que surge não apenas das canções, mas do conjunto completo da figura de RC, não passa pelo samba, pelo batuque, ou por uma base percussiva qualquer - dado estético praticamente eleito como símbolo de nossa singularidade. RC se constrói na antinomia do samba - quase seu oposto. Forçando uma analogia, podemos dizer que no Rio do samba e carnaval, ele é o cristo de braços abertos, impotente e resignado, ameaçadoramente presente, mas sem conseguir impor-se por completo. No Sertão do baião, cultura popular e jagunçagem, ele é o catolicismo fervoroso, Padre Cícero. Nas Minas dos causos populares e mistérios pagãos, ele é a religiosidade cristã sufocante da "Crônica da casa assassinada", de Lucio Cardoso.

Roberto Carlos vai ser o porta-voz da chamada "família brasileira”, aquela entidade identitária que vez ou outra é convocada pelas alas mais conservadoras da sociedade, seja para marchar contra o avanço comunista, seja para se manifestar contra o casamento gay, aborto, ou a legalização da maconha. Roberto Carlos é o cantor de suas desilusões, seus amores, e suas fraturas. Seus planos de casamento, seus casos extraconjugais, sua tristeza. E isso nem o samba tradicional (pela associação com a marginalidade) nem a MPB esclarecida (por seu status bem pensante de tendências progressivas, crítico) podem ser. A "família brasileira” é a dimensão conservadora da sociedade, zelosa protetora da moral e dos bons costumes. RC é expressão de sua educação sentimental: jovens casadoiros, mocinhas recatadas, os conflitos da direita, que não são poucos - a despeito da esquerda. Para entendê-la, é preciso entender RC. Assim como Nelson Rodrigues constrói um painel brilhante da sociedade brasileira e das suas mesquinharias cotidianas a partir de um olhar lançado, não necessariamente à esquerda, sobre os aspectos conservadores do país.

Deve-se então excluir da reflexão sobre o nacional aquilo que lhe é característico, só porque desagradável? Ou ainda, aquilo que nos desagrada não é capaz de propor questões relevantes, ou servir de base para produzir uma obra consistente? Em todo caso, a resposta para essas perguntas não pode ser dada de antemão. Ocultar essa faceta no mínimo leva a uma miopia crítica, e no limite perpetua mecanismos de exclusão baseados não em reflexão, mas em um sistema de manutenção de status quo. Entender não é sinônimo de justificar, mas não se muda uma estrutura sólida da sociedade sem observá-la de perto, sem ouvir sua voz, observar suas fissuras. E qual a imagem da "família brasileira" na obra de RC? Não muito alegre, para dizer o mínimo.

O rei não é aquele que se destaca, mas o que se confunde com a própria norma social, e a nobreza pode ser um fardo. Sua declaração de princípios é "só vou gostar de quem gosta de mim". Bom católico, bom moço, sem defeitos. Sempre igual, sujeito tornado estátua, figuração encarnada da 
norma. Não à toa repete figurinos, repertórios e especiais de fim de ano. Também seu estilo de interpretação foi se tornando mais massificado ao longo do tempo. Mas não é por acaso que o rei brasileiro tende a encarnar o conservadorismo tipicamente nacional. Basta pensar em nossa outra figura real, o maior jogador do mundo, que cinde a própria personalidade por não conseguir condensar, em uma só imagem, o modesto conservadorismo do Edson com o brilhantismo malandro de Pelé, duas faces da mesma moeda ${ }^{20}$.

Para merecer sua coroa real e se tornar o cantor de maior sucesso do país, RC teve de confundir sua figura com a do brasileiro médio, apegando-se à imagem do cidadão comum. E este não é o malandro, aquele que se dá bem subvertendo a ordem em favor de si próprio, muito exaltado enquanto bem cultural, mas caso de polícia na vida real. Não é também o cidadão "esclarecido bem pensante", afinal, para ser isso, é preciso, pelo menos, saber ler e escrever, o que torna essa posição distante para boa parte dos cidadãos do país. Em suma, RC é rei porque é a figuração máxima do sujeito brasileiro comum, o pobre-diabo. Aquele que anula sua própria subjetividade para poder sobreviver em um contexto de precariedade absoluta. Dado um contexto em que reivindicação social é sinônimo de caso de polícia, uma das formas de existência é submeter-se de bom grado ao capricho alheio. No caso, a voz do povo, que é a Dele.

$\mathrm{O}$ que se exige de RC é, pois, a reivindicação inconfessável de anulamento exigida ao cidadão comum. Imperativo que não parte exclusivamente dos poderosos, mas também de seu público fiel. RC acata as regras do jogo, e isso faz dele o rei, mas ao mesmo tempo impede que ele seja reconhecido enquanto sujeito, autor e símbolo de nacionalidade. Logo ele, que o representa tão bem em sua impossibilidade de reconhecimento dessa representação. E não queremos com isso reforçar o argumento de que a obra de RC é fraca por não ter "identidade". Ao contrário, em sua obra, essa posição de autoanulação do "cidadão José" (para usar uma imagem precisa do grupo Racionais) vai ser dramatizada em todas as suas fraturas. Só que um talento deste não pode ser reconhecido, tem que confundir-se com a voz do povo, tomar forma como coisa natural, despojada e sem grandes pretensões. É o seu segredo. A construção da voz do pobre coitado, cujo valor consiste na aparente ausência de qualquer valor que não o da sinceridade e despojamento.

Eis o dilema de RC, a matriz da tensão que sustenta sua obra e sua figura. Ao aderir ao lado conservador da sociedade brasileira, sendo seu

20 Para uma interpretação excelente da figura de Pelé, assim como do futebol brasileiro como veneno e remédio, ver WISNIK, José Miguel. Veneno-remédio - o futebol e o Brasil. São Paulo: Companhia das Letras, 2008. 
porta-voz, ele vai alcançar ampla aceitação (realeza) popular. No entanto, a condição dessa aceitação vai ser sempre ocupar a posição de "coitado", o rei do segundo escalão da música popular, jamais tendo reconhecida sua importância estética ou histórica no interior do cancioneiro nacional:

A bossa nova veio por fim a esse estado de inocência já integrado e ainda pré-MPB; ela criou a cisão irreparável e fecunda entre dois patamares da música popular: o romantismo de massas que hoje chamamos "brega", e que tem em Roberto Carlos o seu grande rei (embora formado como todos os grandes cantores/compositores de sua geração na escuta de João Gilberto), e a música "intelectualizada", marcada por influências literárias e eruditas, de gosto universitário ou estetizado. ${ }^{21}$

A desqualificação inerente a essa figura de submissão impede que RC seja reconhecido por aquilo que representa: o criador da linguagem romântica moderna brasileira, pai da música pop nacional. Um “cidadão José” não se destaca. Não pode exibir marcas de sofrimento pessoal, tem de concordar com tudo e sorrir sempre. Não pode perder uma perna e nem usar roupa escura, negativa. E pode menos ainda ser tornado símbolo nacional, ou modelo de boa arte. É uma figura essencialmente triste.

Excluir RC do panteão dos grandes artistas nacionais (na acepção mais ampla) é pretensamente um gesto de recusa ao conservadorismo. Mas o que existe de conservador nesse gesto de dizer o que é e o que não é representativo do Brasil? O que cabe e o que não cabe nesse conceito? Enxergar o país a partir da ótica proposta pelo compositor de "Detalhes" vai trazer novas questões, apresentar um país diferente, com novos personagens. Mulheres, deficientes, pais de família. RC vai ser um dos primeiros a se aproximar da música Black no Brasil, junto com Erasmo. Ele também vai ser o cantor brasileiro mais escutado na América Latina, outro espaço que normalmente não se integra à ideia padrão de nacionalidade. É o responsável por consolidar a música pop em território nacional, dando forma a um modo de dizer que não passa pelas formas "tradicionais". Além disso, é também o responsável direto por desenvolver a moderna música romântica nacional, sendo a própria personificação do modo de cantar o amor no país depois da transformação da indústria fonográfica nos anos 1950-1960.

Percebe-se que é outra a imagem de país que se insinua caso passemos a vê-lo a partir da ótica carlista. E é urgente que o façamos.

21 WISNIK, J. M. Algumas questões de música e política no Brasil. In: Paulo: Publifolha, 2004. 